
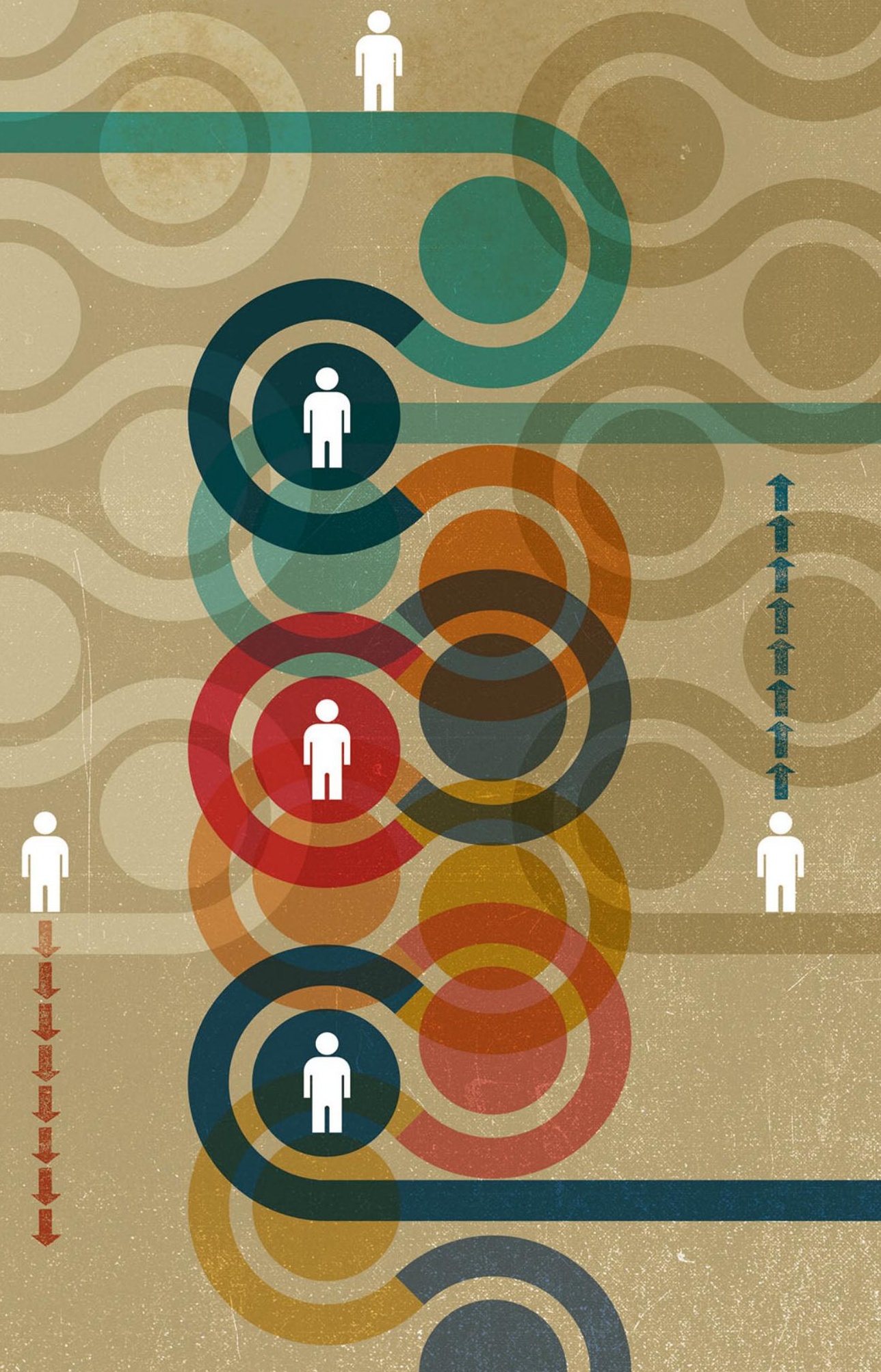


\title{
Ativismo burocrático, políticas sociais intersetoriais e os desafios da inclusão produtiva no Brasil
}

\author{
Bureaucratic activism, intersectoral social \\ policies and the challenges of productive \\ inclusion in Brozil
}

* Arnaldo Provasi Lanzara

\begin{abstract}
Resumo
O caráter heterogêneo do mercado de trabalho no Brasil requer a articulação de políticas públicas que promovam a qualificação profissional dos grupos sem acesso à renda do trabalho. Este artigo analisa como o governo brasileiro, durante o triênio 2011 e 2013, enfrentou os desafios colocados por essa necessária articulação. Programas criados pelo governo brasileiro naquela ocasião, como o Programa Nacional de Acesso ao Ensino Técnico e ao Emprego (Pronatec), atestaram a efetividade das iniciativas intersetoriais no âmbito da qualificação profissional, mobilizando diversas burocracias relacionadas aos setores de política social em torno dos objetivos da inclusão produtiva.
\end{abstract}

Palavras-Chave: inclusão produtiva, mercado de trabalho, intersetorialidade das políticas públicas, burocracia.

\begin{abstract}
The heterogeneous character of the labor market in Brazil requires the articulation of public policies that promote the professional qualification of groups without access to labor income. This article analyzes how the Brazilian government, during the triennium 2011 and 2013, faced the challenges posed by this necessary articulation. Programs created by the Brazilian government at that time, such as the Programa Nacional de Acesso ao Ensino Técnico e ao Emprego (Pronatec), testified to the effectiveness of intersectoral initiatives in the field of professional qualification, mobilizing various bureaucracies related to social policy sectors around the objectives of productive inclusion.
\end{abstract}

Keywords: productive inclusion, labor market, intersectoriality of public policies, bureaucracy.

\footnotetext{
* Doutor em Ciência Política, IESP/UERJ. Pesquisador INCT/PPED. Professor Adjunto de Ciência Política e Políticas Públicas, e coordenador do curso de Administração Pública no Instituto de Ciências Humanas e Sociais -ICHS/ UFF. 


\section{Introdução}

As garantias permanentes ao acesso à renda e ao trabalho são objetivos que devem ser perseguidos simultaneamente pelas estratégias de proteção social dos governos. A eficácia da estratégia de superação da extrema pobreza no Brasil, no período 20032016, deve-se, entre outras coisas, a um ativismo desempenhado pelas burocracias de diversos ministérios na mobilização e articulação de programas, ações e instrumentos de políticas públicas em torno da institucionalização dessas garantias.

No entanto, ainda persistem grandes desafios. Há um expressivo contingente da população brasileira em situação de vulnerabilidade e risco, sem acesso à renda do trabalho ou inserida de forma precária na dinâmica econômica inclusiva. Para enfrentar esses desafios, o governo brasileiro lançou, em 2011, o Programa Nacional de Acesso ao Ensino Técnico e ao Emprego (Pronatec), coordenado pelo Ministério da Educação (MEC). Trata-se de um programa de qualificação profissional que, em conjunto com as ações de combate à pobreza e inclusão produtiva coordenadas pela burocracia do antigo Ministério do Desenvolvimento Social e Combate à Fome (MDS) e de intermediação da mão de obra realizadas pelo Ministério do Trabalho e Emprego (MTE), proporcionou, pela primeira vez, condições de inserção no mercado formal de trabalho para a parcela mais vulnerável da sociedade brasileira.

Embora o Pronatec tenha apresentado algumas falhas de implementação, em grande medida oriundas de sua forma de provisão público-privada nos níveis locais, é inegável que sua articulação com as políticas socioassistenciais mostrou-se promissora quanto aos objetivos de identificar e cadastrar as famílias em situação de vulnerabilidade nas estratégias de inclusão produtiva desenvolvidas no âmbito do programa.

Este estudo está dividido em quatro seções, além desta breve introdução. A segunda seção discorre sobre a importância de se considerar as categorias renda e trabalho como partes integrantes dos sistemas de proteção social, haja vista certa visão que pretende separá-las como categorias estanques de proteção. A terceira seção traça um perfil do mercado de trabalho brasileiro ao destacar os problemas estruturais que tipificam esse mercado, quais sejam: a rotatividade da mão de obra e a ausência de políticas públicas de inclusão produtiva destinadas a grupos sem acesso à renda do trabalho. Com relação a esses problemas, a quarta seção analisa a articulação de uma recente política pública desenvolvida pelo governo brasileiro, o Pronatec, com os serviços socioassistenciais. Apesar de esse programa ter apresentado algumas falhas no que se refere ao seu modo de implementação descentralizado, em que se destaca a forte presença de provedores privados, tal articulação, fruto da integração de iniciativas intersetoriais organizadas por um "ativismo burocrático" nos campos da assistência, educação e trabalho, buscou solucionar os problemas relacionados ao baixo perfil de emprego dos grupos em situação de vulnerabilidade. A quinta e última seção conclui o trabalho. 


\section{Falsas dicotomias: renda básica versus trabalho, igualdade de oportunidades versus igualdade de posições}

Em anos recentes, a perspectiva dos direitos sociais vinculados ao trabalho sofreu duras críticas. Um fatalismo oriundo de uma espécie de resignação circunda o debate em torno desse tema. Segundo algumas abordagens, a crise estrutural do pleno emprego, em diversas sociedades, teria interrompido definitivamente o ciclo de expansão do trabalho assalariado e protegido. Diante desse fato, não restariam mais alternativas de proteção aos "deserdados do mundo do trabalho". Estes, como única alternativa de proteção, deveriam se conformar à provisão de uma renda básica, independente das situações de trabalho.

Várias correntes de questionamento radical do trabalho e dos direitos a ele associados nutrem-se desse fatalismo, procurando dissociar trabalho e renda. De componentes outrora indispensáveis e complementares da política social num sentido lato, as categorias trabalho e renda são vistas agora como contrapostas e mutuamente exclusivas em suas implicações redistributivas. Tal visão é endossada tanto nas teses que pronunciam explicitamente o "fim do trabalho" como fundamento da vida social, mais difundidas nos países centrais (Méda, 1995; Rifkin, 1995), quanto nas teses obstinadas em apontar a impossibilidade de replicar a "sociedade salarial" (Castel, 1998) nas condições do "atraso periférico". Enfim, todas essas teses são unanimes em ressaltar a necessidade de superar o assalariamento protegido por técnicas alternativas de redistribuição, menos sujeitas aos infortúnios do trabalho.

Entretanto, quando concebida como único espaço para a redistribuição, a renda básica, separada da proteção do trabalho, tende a dissociar a esfera da atividade econômica e a esfera da solidariedade (Fitoussi e Rosanvallon, 1996). Paradoxalmente, seus defensores à esquerda e à direita a exaltam por esse motivo. Essa dissociação encontra-se presente tanto nas teorias libertárias das "microcomunidades de bemestar" (Nozick, 1974) quanto nas teorias beveridgeanas que pretendem "liberar o homem da necessidade". Um aspecto problemático de ambas as teorias é que elas terminam por eximir o mercado de todas as suas obrigações sociais ao não reconhecerem, ou omitirem, o papel das convenções relacionadas ao trabalho na limitação dos rigores da competição capitalista e dos riscos sociais. Além disso, tais teorias negligenciam o fato de as necessidades sociais serem contingentes e variáveis assim como as medidas redistributivas adotadas para ir de encontro a essas mesmas necessidades.

Dependendo da sociedade em questão, os instrumentos de proteção social devem balancear suas medidas redistributivas de acordo com a variação das necessidades sociais, combinando provisões universais, não relatadas ao trabalho, e benefícios de seletividade moderada (contributivos e vinculados ao trabalho). A legislação social do Estado fica defasada em relação à realidade quando se prefigura de vez as necessidades dos indivíduos e quando se propõe uma separação institucionalizada 
das categorias renda e trabalho. Diante desse quadro, o máximo que a política social pode fazer é promover "um divórcio indenizado entre o econômico e o social" (Fitoussi e Rosanvallon, 1996:190).

É importante lembrar que na sociedade salarial o emprego estável de duração indeterminada, além de configurar-se como vetor da integração social e da cidadania, tornou-se o principal mecanismo de distribuição da renda. Longe, portanto, de prender os trabalhadores nas rédeas da sujeição total ao mercado, tal sociedade conferiu-lhes autonomia ao provê-los com os benefícios da proteção social.

Nessa discussão, importa destacar que os mercados de trabalho regulados não se configuraram como "simples mercados", compreendendo uma densa rede de instituições e políticas públicas. A efetividade dessas redes foi e é, em grande medida, responsável por conferir estabilidade ao assalariamento formal, sobretudo em sociedades em que esse assalariamento representou amplo acesso dos trabalhadores a subvenções extratrabalho sob a forma de proteção social.

Portanto, à luz da experiência dos países que universalizaram a norma salarial, um mercado de trabalho regulado pode ser tipificado pelo alcance e efetividade de suas proteções. Pode-se dizer que esse mercado opera pautado por certas "convenções de justiça" (Boltanski e Thévenot, 2006) que além de limitarem os rigores da competição capitalista oferecem um mínimo de segurança ontológica às expectativas daqueles que nele se integram.

Devido ao fato de as exigências da sociedade individualista fundada no mérito e na competição buscarem justificativa em algum critério de justiça, esta justificativa encontrava suporte nas instituições que conectavam competências profissionais, carreiras e proteção social. Essa conexão se realizava num mercado de trabalho estruturado por políticas de seguridade social, normas jurídicas de proteção do trabalho, convenções coletivas e por sistemas de educação, treinamento vocacional e de aprimoramento das competências profissionais. Em outras palavras: para se tornarem críveis e não se constituírem em simples promessas, tais exigências retiravam sua legitimidade das instituições públicas de educação e de regulação do trabalho. Pois na era do capitalismo regulado havia também um ciclo de vida protegido, que se caracterizava por uma "passagem pré-programada", quase automática, da escola ao emprego (Dubar, 1998).

Contudo, ao apagar os registros que tornavam críveis a proteção do ciclo de vida e a composição de trajetórias seguras da escola para o trabalho, o movimento de desregulamentação dos mercados de trabalho, verificado nos últimos anos, colocou em xeque a relativa igualdade de posições assegurada pela sociedade do trabalho. Esse movimento, embora recrudescido por mudanças econômicas, tem nítidas influências ideológicas, decorrendo de uma ideia, fortemente informada pelo imaginário liberal, que tende a considerar esgotados os efeitos dessa igualdade de posições. Esta seria substituída por uma hipotética "igualdade de oportunidades" que, no atual cenário, conciliaria os imperativos éticos da competitividade econômica com os requisitos de 
equalização das chances de vida. O principal problema é que tal imaginário tende cada vez mais a confundir igualdade de oportunidades com capacidade de "autoproteção" dos indivíduos. E é por essa razão que a igualdade de oportunidades desfruta de uma vantagem filosófica que se mostra muito mais atraente e inquestionável nos dias de hoje (Dubet, 2010). Tal vantagem decorre da ideia de que os"vencidos" pela competição capitalista merecem o seu destino por não terem se utilizado corretamente de suas chances e oportunidades. Pois na sociedade competitiva recai sobre o indivíduo o duplo imperativo de um contínuo aperfeiçoamento e de uma estima permanente de si mesmo, que são os mecanismos de ativação tanto da vida pessoal como do êxito profissional (Fitoussi e Rosanvallon, 1996:44).

As chamadas "políticas de workfare" são a expressão mais cabal desse duplo imperativo aplicado aos mercados de trabalho (Dwyer 2004; Dean, 2007). Elas difundem a crença em uma "competição equitativa", funcional aos imperativos do mercado, já que os aptos para o trabalho foram treinados para enfrentar e aceitar as duras provas que a competição exige. Recicle-se para um mercado de trabalho competitivo, flexível e sem proteção e aceite os riscos desse mercado como um desafio pessoal. Eis o novo ditado. É através dessas políticas que o direito ao trabalho, em diversas sociedades, vem sendo gradativamente permutado por uma espécie de "garantia à empregabilidade" voltada exclusivamente para promover as competências de indivíduos aptos a se engajar num mercado de trabalho caracterizado por uma mobilidade desregulamentada e sem proteção. Nesse sentido, o acesso ao emprego torna-se uma função direta da própria capacidade do indivíduo de se manter fora dos períodos prolongados de desocupação.

A igualdade de oportunidades também produz certas ilusões ao confiar unicamente ao sistema educativo a imperiosa missão de realizar suas promessas a cada nova geração, sem se importar com o caráter multidimensional das desigualdades e com a cada vez mais evidente cristalização das condições iniciais desiguais entre os indivíduos (Dubet, 2010:84). Assim, quanto mais se confia nessa missão providencial mais ela se transforma numa espécie de panaceia, e mais se pensa que as gritantes desigualdades em termos de trajetórias escolares e profissionais são justas e que decorrem apenas do mérito individual.

O fato é que a igualdade de posições deve ser prioritária porque engendra uma sociedade menos elástica às incertezas do mercado e às desventuras da competição individual. Portanto, mesmo que o Estado não se desinteresse totalmente pelo destino dos excluídos, e que as políticas públicas promovam uma radical igualdade de oportunidades mediante a "inclusão" tópica e parcial das pessoas nos sistemas de educação e trabalho, haverá poucas chances de essas mesmas pessoas permanecerem protegidas ao longo dos seus ciclos de vida se não forem integradas em posições mais estáveis. É por isso que nas sociedades salariais densamente estruturadas por estatutos de proteção, e em tempos não muito longínquos, as palavras "inserção" ou "inclusão" 
faziam pouco sentido, visto estar o imaginário da proteção do trabalho centrado nos fatores que garantiam uma mobilidade regulada das trajetórias profissionais.

Mas quais são as expectativas de integração no mundo do trabalho que subjazem em sociedades estruturalmente desiguais, como a brasileira, que não desfrutaram das proteções que qualificaram as sociedades descritas acima? Se nestas ainda prevalecem as expectativas em torno dos legados produzidos pelas instituições que tipificaram o mundo seguro, no contexto específico do mercado de trabalho de sociedades como a brasileira valem outras expectativas. Estas estão muito mais centradas nas noções de inclusão produtiva e inserção qualificada enquanto primeiras aspirações de acesso ao mundo do trabalho regulamentado. Isso é particularmente válido para contingentes populacionais nada desprezíveis dessas sociedades, devido à pujança de situações precárias e intermitentes de trabalho.

\section{Brasil: desafios da inclusão produtiva num mercado de trabalho pouco estruturado}

Em mercados de trabalho como o brasileiro, o inchaço do setor terciário, os baixos salários, e especialmente a alta rotatividade do emprego e o subemprego, não são fenômenos novos e excepcionais, creditados apenas ao movimento global e mais recente de desregulamentação. Esses fatores, no Brasil, possuem profundas raízes históricas e decorrem do modo de acumulação capitalista que prevaleceu no país; um modo de acumulação predatório e hostil ao direito dos trabalhadores, que mesmo em sua expressão dinâmica e moderna se constituiu em simbiose com a depressão dos salários (Oliveira, 1972).

O que caracteriza estruturalmente as relações de trabalho no Brasil não é apenas a mobilidade dos trabalhadores entre posições "formais" e "informais", que, aliás, é bastante intensa. O contínuo fluxo dos trabalhadores entre essas posições deixa entrever que a dita formalização no Brasil, dada a rarefação de suas regulações, pouco diferencia quem é empregado ou subempregado, terminando por obscurecer a fragilidade dos vínculos de trabalho produzidos pela economia. Vale ressaltar que uma intensa mobilidade também atinge os mais vulneráveis - aqueles sem acesso à renda do trabalho - e se reflete na volatilidade das posições dos grupos que gravitam entre situações de pobreza extrema e de acesso intermitente à renda. Na verdade, a estrutura sobre a qual se apoiou o desenvolvimento econômico do país nunca gerou posições assalariadas para todos os participantes/postulantes do mercado de trabalho. Para um contingente expressivo dos trabalhadores brasileiros, a construção de mecanismos alternativos e não assalariados de obtenção de meios de vida foi e continua sendo a regra e não a exceção (Cardoso, 2013).

A pouca abrangência das regulações criadas pelo Estado para proteger o trabalhador fez com que o vínculo formal de trabalho no Brasil, mesmo rarefeito e excessivamente plástico às conjunturas econômicas, se revestisse de um caráter fortemente 
simbólico (Guimarães, 2011). Possuir um trabalho registrado para a grande maioria dos trabalhadores brasileiros significa ter um emprego protegido pela Justiça do Trabalho e pelo seguro social, ou seja, significa a garantia do acesso dos trabalhadores à justiça nos litígios contra o patronato e o acesso à renda para situações fora do mercado de trabalho. Aliás, são esses dois suportes de proteção que sempre conferiram atratividade ao engajamento de parte expressiva da população no assalariamento formal. E desde que foram criados, há mais de oito décadas, representaram para esse contingente a única possibilidade do "direito a ter direitos" (Cardoso, 2010).

Até a Constituição de 1988, o acesso da população aos benefícios sociais, como previdência e saúde, estava restrito aos formalmente integrados no mercado de trabalho. O caráter estritamente contributivo do sistema de proteção social brasileiro deixava em descoberto grande parte da população do país, que encontrava sérias dificuldades para se integrar no núcleo regulado do mundo do trabalho, com "todos os direitos" que este oferecia. O acesso a esses direitos, diga-se, não representava nenhum "privilégio", visto estarem os incluídos no mundo do trabalho sujeitos a uma vigência precária desses mesmos direitos.

A Constituição de 1988 reconfigurou o sistema de proteção social brasileiro ao garantir à população o acesso a vários direitos sociais universais, até então inéditos. Desde então, assiste-se a um importante movimento de juridificação de novos direitos e de incremento das políticas sociais para a população brasileira. Este movimento, embora não isento de retrocessos, trouxe significativos impactos para o mercado de trabalho. Dentre esses impactos, destaca-se a ampliação significativa da cobertura previdenciária e assistencial, com o consequente aumento das transferências monetárias, especialmente daquelas vinculadas ao salário mínimo (Cardoso Jr. e Jaccoud, 2005). Também significativas foram as medidas previstas no texto constitucional que, direta e positivamente, afetaram o trabalho, como os programas de intermediação da mão de obra, o seguro-desemprego e o abono salarial. ${ }^{1}$

Contudo, ao passar de mais de duas décadas, persistem certos problemas estruturais, como a rotatividade do emprego, que deploram as chances de o trabalhador brasileiro trilhar uma trajetória profissional estável e segura. Essa rotatividade é produto de dois tipos de flexibilidade existentes no mercado de trabalho do país: a "flexibilidade quantitativa", provocada por uma elevada oferta de força de trabalho pouco qualificada; e a "flexibilidade contratual", causada por uma insuficiência de mecanismos institucionais inibidores da demissão imotivada (Dieese, 2011:49).

A fragilidade das relações formais de trabalho lança luz sobre a persistência no país de enorme contingente de pessoas inseridas de forma precária na dinâmica econômica inclusiva. Isso também diz respeito à estreita base de mobilidade para posições estáveis no mercado de trabalho proporcionada aos jovens. No Brasil, homens e mulheres se inserem prematuramente no mercado de trabalho. Tal inserção, contudo, quase sempre se faz através de ocupações não registradas e antes de parte significativa dos jovens de ambos os sexos completarem sua formação escolar. 
Em razão disso, as trajetórias ocupacional e escolar são marcadamente conviventes para a maioria dos adolescentes e jovens brasileiros (Hasembalg, 2003). Há, portanto, uma dupla defasagem a macular a transição para a vida adulta dos jovens brasileiros: defasagem de credenciais educacionais adequadas e, correlato a isso, defasagem de postos de trabalho estáveis. As primeiras experiências profissionais de grande parte desses jovens têm como destino certo o trabalho desprotegido (não registrado ou por conta própria), funcionando como um repositório de trabalho farto, ocasional e barato. E é grande a probabilidade desses jovens permanecerem dentro desse repositório, já que sua condição instável no mercado de trabalho geralmente propaga-se para sua vida adulta (Guimarães, 2006).

Mesmo durante o último ciclo de recuperação do emprego formal da economia brasileira, observou-se forte trânsito entre posições estáveis e instáveis, particularmente entre os jovens. Entre 2010 e 2011, segundo dados compilados por Cardoso (2013), não era desprezível o número de indivíduos que, tendo uma ocupação formal em 2010, estava em posições instáveis em 2011. De acordo com esses mesmos dados, baseados na Pesquisa Mensal de Emprego (PME), o emprego "formal" de característica mais instável estava ocupado por jovens homens de 15 a 19 anos, sendo que $31 \%$ desses jovens deixaram seus empregos no curtíssimo espaço de um ano, 1/3 dos quais para ocupar posições informais. Semelhante movimento de migração de posições formais para informais também foi observado para os jovens de 20 a 24 anos no mesmo período, sendo a informalidade o destino de $40 \%$ desses jovens (Cardoso, 2013:89).

Vale ressaltar que o fenômeno da rotatividade do emprego no Brasil esteve ligado, entre outras coisas, à ausência de políticas mais incisivas para o mercado de trabalho - políticas que envolvessem de forma articulada os sistemas de renda, educação e emprego. Durante vários anos, a inexistência de um sistema público de emprego com capacidade de processar, coordenar e capilarizar informação, mediante agências públicas espalhadas por todo território nacional, acirrou o fenômeno da precarização e rotatividade do trabalho. É em razão dessa ausência que se tornou prática corrente entre os trabalhadores brasileiros recorrer a redes privadas e informais de obtenção de emprego. Nessas redes, porém, os critérios de alocação de emprego dependem da difusão da informação entre indivíduos que já possuem certas competências profissionais, sendo o êxito na obtenção de emprego sob esta modalidade de alocação de trabalho proporcional à densidade dos vínculos entre esses indivíduos. O inverso ocorre entre os grupos menos organizados, mais pobres, menos escolarizados e que encontram sérias dificuldades para se inserir em trajetórias ocupacionais estáveis e seguras (Guimarães 2006). Os problemas que afetam esses grupos, como a escassez de informação, tendem a ser desconsiderados pelas estratégias convencionais de intermediação da mão de obra, já que tais grupos não se enquadram no perfil do demandante "clássico" de emprego. 
Apesar do problema da rotatividade do emprego atingir vários setores de atividade, e afetar inclusive os trabalhadores mais integrados no mercado formal de trabalho, são os trabalhadores de menor remuneração, baixa escolaridade e, correlato a isso, com perfis de baixa qualificação profissional, que mais sofrem as consequências de tal fenômeno.

Ao lado desses problemas, saliente-se a total ausência no Brasil, até meados da década de 2000, de programas de qualificação profissional desenhados para lidar com as vulnerabilidades da população mais pobre e sem acesso à renda do trabalho. As ações de qualificação profissional ganharam vulto somente após a Constituição de 1988. Entretanto, os programas nesse âmbito, até 2003, reproduziram os mesmos problemas ao alocar os trabalhadores desocupados em cursos de qualificação que pouco contribuíam para aprimorar suas competências profissionais, havendo uma forte dissociação entre as políticas de renda, educação e trabalho. As ações voltadas a esse público competiam entre si e estavam isoladas em mais de uma dezena de ministérios.

Durante a década de 1990, tornou-se prática corrente repassar recursos destinados à qualificação profissional a municípios com pouca ou quase nula capacidade de implementar políticas. Tal era o caso dos municípios desprovidos de redes públicas de ensino profissional, que, sendo os responsáveis por selecionar os ofertantes dos cursos de qualificação, acabavam por contemplar e remunerar uma oferta de qualidade inferior e de probidade duvidosa. Em suma, não havia critérios técnicos definidos pelo Governo Federal para o repasse de recursos e tampouco instrumentos eficientes de monitoramento e controle que atestassem a efetividade dessa política.

Além disso, as estruturas operacionais e de gestão da política de qualificação no Brasil eram ineficientes no que tangia à integração de iniciativas. O desafio estava, portanto, em superar alguns problemas de coordenação burocrática para se implementar uma política integrada de qualificação profissional de âmbito nacional e articulada entre os diferentes ministérios.

Conferir emprego e proteção social aos trabalhadores mais vulneráveis tornouse um dos principais objetivos da coalizão de centro-esquerda que governou o país entre 2003 e 2016. Para lograr esses objetivos, e de modo a resgatar uma dívida social historicamente pendente, os governos da coalizão liderada pelo Partido dos Trabalhadores (PT) - os governos de Luiz Inácio Lula da Silva (2003-2010) e de Dilma Rousseff (2010-2016) - ampliaram significativamente o escopo das políticas públicas destinadas a esse público. Merecem destaque as políticas públicas de emprego, trabalho e renda, mas também e primordialmente, os programas de transferência de renda, como o Programa Bolsa Família (PBF), responsável por tirar milhões de brasileiros da indigência e da pobreza.

Não obstante o fato de ser prioritária a preocupação com os excluídos, o combate às desigualdades no Brasil foi realizado sem as clivagens habituais que em outras partes, e informadas pelas perspectivas citadas na seção anterior, circunscrevem os temas 
relatados à renda e ao trabalho, separando-os como objetos estanques de proteção. Comparadas às políticas produzidas em outros contextos, e mesmo operando sob fortes restrições orçamentárias, as políticas de assistência não contributivas perseguidas no Brasil recente, e as iniciativas de proteção do mercado de trabalho, como as políticas de valorização do salário mínimo, de incremento das negociações coletivas, de fiscalização do trabalho e de inclusão previdenciária, foram ativadas e articuladas mediante reforço das capacidades burocráticas do Estado de implementar políticas sociais (Bichir, 2015; Lanzara, 2015).

Apesar das conquistas logradas com o movimento de formalização do trabalho entre os anos 2004 e 2014 (fruto do maior crescimento da economia), a falta de empregos de qualidade para a camada mais pobre da população afigurou-se como um fenômeno durável, persistindo elevado percentual de trabalhadores na informalidade e sem proteção. Cabe destacar que à medida que avançava o combate à pobreza tornava-se cada vez mais evidente que os programas de transferência de renda, como o PBF, requeriam articulação com outras políticas sociais, especialmente com as políticas de inclusão produtiva, haja vista o problema da volatilidade de renda das famílias inscritas nesses programas (Soares 2009). Tornou-se patente, portanto, o desafio de criar políticas mais incisivas de qualificação profissional voltadas a esse público

É nesse contexto que se insere a criação do Pronatec, em 2011, mobilizando esforços de diversas burocracias ministeriais envolvidas com o tema em questão. $\mathrm{Na}$ próxima seção se discutirá como as políticas públicas de inclusão produtiva, como o Pronatec, foram articuladas com as políticas socioassistenciais, dentro de uma estratégia de ativismo burocrático intersetorial, para enfrentar o problema da baixa qualificação profissional da população mais pobre do país.

\section{Ativismo burocrático, medidas socioassistenciais e o Pronatec}

As condições que configuram o surgimento de um ativismo do Estado no campo da proteção social se vinculam ao advento de burocracias públicas determinadas a enfrentar situações bastante adversas do ponto de vista da implementação efetiva de políticas sociais, mesmo na ausência de demandas políticas explícitas. Esse "ativismo burocrático" é particularmente importante para sociedades estruturalmente desiguais como a brasileira, em que as pautas reivindicativas de alguns grupos permaneceram por muito tempo estagnadas e confinadas a espaços marcados pela privação e pela inércia. O desafio dessas sociedades, portanto, é fazer com que suas burocracias públicas penetrem de um modo mais rotineiro nesses espaços, solapando os efeitos inerciais das "não decisões" acumuladas no tempo, de modo a gerar relações que ativem um limiar de sensibilidade social nos grupos que aí convivem sem se identificar (isto é, sem perceber suas desigualdades circundantes e sem conhecer seus direitos sociais fundamentais). 
Admitir o protagonismo das burocracias, contudo, não significa desconsiderar questões referentes à legitimidade dos seus instrumentos de implementação de políticas. Tais instrumentos, como os orçamentos, as estatísticas, os cadastros, as inscrições estatutárias, os critérios de elegibilidade que definem o acesso de segmentos da população a uma determinada política, não são dispositivos dotados de "neutralidade axiológica" (Lascoumes; Le Galès, 2007). São eles na verdade que estruturam as políticas, abrindo novas perspectivas à dinâmica dos interesses dos atores sociais. Constituem-se ainda em dispositivos técnicos e sociais, que, em si mesmos, expressam diferentes tipos de relacionamento Estado/sociedade. Além disso, se configuram como importantes ferramentas de "legibilidade do social" (Idem, 2007), capazes de representar as diversas situações sociais que tangenciam o processo de implementação de políticas, determinando os cursos de ação dos diferentes públicos imersos nessas situações.

É importante destacar que um dos principais objetivos desses instrumentos é produzir ação coletiva; seus efeitos são particularmente importantes para a mobilização de grupos cujos problemas"não possuem consistência sociológica imediata"(Rosanvallon, 2008). Isto é, eles são fundamentais para a superação dos problemas de grupos que, por sofrerem fortes privações sociais, se encontram impedidos de se engajar em ações coletivas identificadoras de direitos. Em algumas circunstâncias, é necessário que esses instrumentos promovam essa mobilização, seja mediante "induções burocráticas", seja através de uma abordagem intersetorial e coordenada desses problemas pelos poderes públicos. É através desses instrumentos que se promove uma articulação mais permanente entre diferentes burocracias, atores políticos e sociais, com vista a suplantar as dificuldades que esses grupos possuem de acessar seus direitos sociais básicos.

Portanto, ativismo burocrático no campo da proteção social significa que os agentes do Estado mobilizam seus instrumentos de política pública para implementar uma "política de direitos" em consonância com as carências de grupos específicos e em sintonia com a dinâmica interdependente dos problemas sociais.

No Brasil, as políticas de qualificação profissional se beneficiaram desse ativismo desempenhado por um tipo de reordenamento da capacidade de implementar políticas sociais conduzida pelo Estado nos últimos anos. A criação do Programa Nacional de Acesso ao Ensino Técnico e Emprego - Pronatec (Lei 11.5013/2011) foi emblemática desse reordenamento, buscando expandir, interiorizar e democratizar o acesso da população à qualificação profissional (Brasil 2012). Um dos principais diferenciais desse programa refere-se ao seu desenho e forma de implementação. Quanto ao seu desenho, foi nítida a diferença em relação aos programas anteriores de qualificação profissional, já que ele foi ajustado aos diferentes perfis dos seus destinatários. Com relação à sua forma de implementação, esta foi fruto de iniciativas intersetoriais promovidas e pactuadas pelas burocracias de diferentes ministérios, sobretudo das áreas de educação, trabalho e assistência. 
Quando o programa foi criado, este estava a cargo da Secretaria de Educação Profissional e Tecnológica do Ministério da Educação (SETEC/MEC). Mas as ações específicas de qualificação profissional e inclusão produtiva nele previstas estavam compartilhadas entre vários ministérios, destacando-se, além do Ministério da Educação (MEC), o Ministério do Trabalho e Emprego (MTE) e o Ministério do Desenvolvimento Social e Combate à Fome (MDS).

Os cursos de qualificação fornecidos pelo programa foram integralmente financiados pelo Governo Federal e ofertados gratuitamente por instituições da Rede Federal de Educação Profissional, Continuada e Tecnológica e das redes estaduais e municipais. Vale lembrar que apesar de insuficientes para atender as demandas de qualificação profissional da população, essas instituições passaram por um movimento inédito de expansão durante os governos da coalizão liderada pelo Partido dos Trabalhadores (PT).

Também foram inscritos no Pronatec, como ofertantes privados de cursos de qualificação, as instituições vinculadas aos serviços Nacionais de Aprendizagem, o chamado Sistema S (Senai, Senac, Senar e Senat). ${ }^{2}$ Nesse aspecto, um acordo inédito firmado entre o MEC, o MTE e o Ministério da Fazenda (MF) com os ofertantes privados estabeleceu que parte das receitas compulsórias líquidas arrecadadas pelo Sistema $S$ financiasse a oferta gratuita de cursos de qualificação para a população de baixa renda, especialmente para os beneficiários do PBF. Esse acordo de gratuidade buscava alinhar parte da oferta de cursos de qualificação providos pelo Sistema S às estratégias governamentais de inclusão produtiva, que eram parte do Pronatec, pois é sabido que as entidades filiadas ao Sistema $\mathrm{S}$, embora guardem personalidade jurídica de direito privado, foram instituídas pelo poder público para ministrar cursos profissionalizantes, sem fins lucrativos, para os trabalhadores da iniciativa privada. Porém, parte desses cursos é custeada por contribuições compulsórias que as entidades patronais descontam dos salários dos trabalhadores, havendo cobrança de mensalidade para frequência nos cursos.

Cabe lembrar que desde o surgimento do Sistema S na década de 1940, os empresários brasileiros se opuseram veementemente aos intentos de o Estado ampliar esses cursos por meio de acordos de gratuidade. Embora surtindo poucos efeitos, o acordo de gratuidade instituído no âmbito do Pronatec visou atenuar as resistências das entidades patronais à oferta gratuita de cursos profissionalizantes destinada aos segmentos da população sem acesso ao mercado formal de trabalho.

Não obstante esses problemas, o aspecto mais importante a ser ressaltado é que a implementação do Pronatec nos municípios mais pobres seria impensável sem a constituição prévia de uma institucionalidade propiciada pelas ações desenvolvidas pelo governo brasileiro no campo da assistência social.

Nesse sentido, vale ainda lembrar que o programa somente adquiriu relevo em decorrência do lançamento do Plano Brasil Sem Miséria (BSM) (Decreto n 7.492/2011), cujo desenho e diretrizes de implementação foram traçados pela burocracia do 
antigo MDS. ${ }^{3}$ Como parte integrante do BSM, o Pronatec Brasil sem Miséria (Pronatec/ BSM) tinha como meta atender os objetivos de inclusão produtiva da população mais vulnerável (Brasil, 2013). O BSM conferiu escala e alcance a esses objetivos, visto que a adesão das esferas locais de governo ao Pronatec/BSM foi realizada em razão da existência de uma rede de serviços socioassistenciais instalada nos municípios, com forte capacidade de processar informações e de mobilizar sua burocracia. Assim, o programa em questão se beneficiou do sistema de informação disponibilizado pela assistência nos municípios e da existência de interlocutores nas prefeituras, que eram integrantes dessa área, para mobilizar e inscrever o público nos cursos de qualificação (Costa et al. 2014, p.3).

O Pronatec/BSM contou ainda com apoios nas Secretarias Municipais de Assistência Social (SMAS) e no Programa Nacional de Promoção do Acesso ao Mundo do Trabalho (Acessuas). Tais apoios foram cruciais para identificar as demandas de inclusão produtiva nos municípios mais pobres e apresentá-las as instituições ofertantes que integravam o programa.

Portanto, as experiências de municipalização das políticas de assistência social, em grande medida consolidadas pela recente implementação do Sistema Único de Assistência Social (SUAS) no país, assim como sua abrangência nacional e capilaridade territorial, tornaram o SUAS o principal parceiro da implementação do Pronatec/BSM, levando as informações pertinentes a esse programa até o seu público-alvo (Costa et al. 2014, p.5).

Como se pode observar, a participação da assistência social nas estratégias de inclusão produtiva do Pronatec, sobretudo urbana, assumiu um papel central. Não é exagero afirmar que a eficácia de tais estratégias foi proporcional ao êxito dos instrumentos de política pública colocados em curso pela burocracia do antigo MDS e agrupados em torno dos serviços socioassistenciais recentemente desenvolvidos pelo governo brasileiro.

Não é intuito deste trabalho remontar a trajetória da política de assistência social no Brasil. Cabe apenas enfatizar a recente "conjuntura crítica" de mudança no tradicional modo de operação dessa política com a criação, em 2005, do Sistema Único de Assistencial Social (SUAS), que conferiu faticidade programática aos dispositivos constitucionais previstos na Lei Orgânica da Assistência Social (LOAS) de 1993.

É importante salientar que a operação da política de assistência social prevista na Constituição somente adquiriu relevo nos últimos anos. Isso se deve à disposição dos governos da coalizão de centro-esquerda, liderada pelo Partido dos Trabalhadores (PT), de enfrentar os problemas gerados pela pobreza em suas múltiplas interfaces.

Compreendendo um conjunto de iniciativas visando à institucionalização das políticas de seguridade social no país, a LOAS, em seu artigo $2^{\circ}$, prevê, como um dos objetivos da Assistência Social, a promoção da integração das políticas de assistência e trabalho. Visa, portanto, articular políticas sociais setoriais que tangenciam os universos contributivo e não contributivo da proteção social brasileira. Constituído para 
implementar a LOAS, o SUAS conferiu um novo tratamento a questão social brasileira ao eleger a renda e o trabalho como objetivos indissociáveis de proteção social. Criado a partir de um nítido esforço governamental de articular burocracias envolvidas na implementação das políticas de assistência social, antes dispersas, o SUAS organiza, de forma descentralizada, os serviços socioassistenciais no país destinado à prevenção e à erradicação das situações de vulnerabilidade e risco social (Brasil, 2012).

Em 2012, o Conselho Nacional de Assistência Social estabeleceu na Resolução CNAS n 33/2011 que a promoção da integração ao "mercado de trabalho" no campo da assistência deve ser entendida como integração ao "mundo do trabalho", por ser esse um conceito mais amplo e adequado aos desafios da política de assistência social (Brasil, 2012). Dessa forma, o acesso ao "mundo do trabalho" não é responsabilidade exclusiva dessa política, mas resultado da ação intersetorial de diversas políticas públicas visando tal objetivo.

Vale ainda ressaltar que a integração de iniciativas nos campos da assistência e da inclusão produtiva não se tornaria realidade sem os instrumentos de política pública introduzidos pela burocracia do antigo MDS. Um desses instrumentos foi o Cadastro Único para Programas Sociais do Governo Federal (Cadastro Único) ${ }^{4}$, que identifica e caracteriza as famílias de baixa renda beneficiárias dos programas sociais federais de transferência de renda, como o PBF.

Desde que foi regulamentado (Decreto n. 16.135/2007), o Cadastro Único se consolidou como um importante registro de normatização, monitoramento e controle das políticas de assistência implementadas pelos governos estaduais e municipais. Ao lado disso, cumpriu um destacado papel na formulação de políticas de inclusão produtiva voltadas à população de baixa renda. É importante registrar que a inscrição das famílias no Cadastro Único é atribuição dos municípios. Nesse aspecto, as prefeituras tiveram papel central na gestão local do Pronatec/BSM (Brasil 2013). Ao levantar informações pertinentes aos grupos sem acesso à renda do trabalho em diversos municípios, o Cadastro Único gerou subsídios para a elaboração do PronatecBSM, reduzindo os custos de informação e de acesso da população mais vulnerável aos cursos de qualificação profissional.

Pode-se dizer que o Cadastro Único tornou a leitura da realidade social brasileira mais inteligível, constituindo-se num importante instrumento de inscrição da população mais vulnerável aos programas sociais de assistência e de inclusão produtiva. Foi através da utilização desse instrumento que os potenciais beneficiários das políticas públicas de inclusão produtiva no Brasil adquiriram visibilidade, podendo ao menos ter acesso às informações para se engajar no mercado formal de trabalho.

Como um resultado, entre 2011 e 2014, mais de 1.1 milhão de pessoas se matricularam no Pronatec/BSM. Desse contingente, mais de 430 mil (aproximadamente $37,6 \%$ do público total de inscritos) estavam no mercado formal de trabalho, muitos dos quais experimentaram um emprego formal pela primeira vez (Costa et al. 2014). 
Apesar dos êxitos do programa, persistiram grandes desafios. Um desses desafios diz respeito ao recente desmantelamento da burocracia do MDS, promovida pela nova coalizão política (conservadora) que ascendeu ao governo com o processo de impeachment da presidente Dilma Rousseff em setembro de 2016. Esse desmantelamento ameaça a continuidade do programa, especialmente para a população mais vulnerável, visto que a burocracia do MDS detinha um forte poder de coordenação das iniciativas de inclusão produtiva que atuavam em articulação com as medidas socioassistenciais.

Ao lado disso, alguns estudos produzidos pela burocracia do antigo MDS constataram a existência de significativos obstáculos à inserção da população mais vulnerável ao Pronatec/BSM, especialmente no nível local, reacendendo a discussão sobre o legado privado das políticas de qualificação profissional existentes no Brasil (Varella et al. 2015; Amâncio 2015). Tais obstáculos provinham da dificuldade de o Pronatec/BSM realizar uma articulação estratégica entre a vocação econômica dos diversos municípios e a capacidade de os mesmos ofertarem cursos adaptados aos diferentes perfis ocupacionais da população-alvo. Nesse sentido, constatou-se que parte considerável dos cursos de qualificação ofertados pelas unidades provedoras que integravam o Pronatec/BSM no âmbito local - majoritariamente privadas - não se adequava às especificidades do público-alvo do programa e/ou às demandas dos mercados locais de trabalho.

Outros problemas levantados por esses estudos deixaram entrever o caráter pouco efetivo dos mecanismos de coordenação federativa e a baixa pactuação política no âmbito do programa para sua implementação nos diversos municípios brasileiros, visando maior controle da oferta privada dos cursos de qualificação (Amâncio 2015).

Não deixa de ser sintomático o fato de esses problemas se reportarem aos ofertantes privados de cursos. Pois é necessário ressaltar que em um país federativo e desigual como o Brasil, em que vários munícipios carentes de infraestrutura pública de provisão de serviços sociais estão obrigados constitucionalmente a prover uma série de políticas sociais setoriais, são as organizações privadas que detêm muitas vezes o virtual monopólio da capacidade de oferta dessas políticas no nível local. Assim, parte considerável da oferta de cursos de qualificação prevista pelo Pronatec/BSM para os municípios teve de ser contratada junto aos provedores privados (Sistema S e terceiro setor) -, o que, obviamente, reduziu o poder de indução da oferta pública de cursos de qualificação por parte da gestão municipal (idem, 2015).

Em suma, as lacunas da coordenação do Pronatec/BSM, especialmente nos níveis locais, favoreceram a ação autônoma e sub-reptícia dos ofertantes privados. Estes, em alguns casos, captaram estrategicamente os recursos repassados pelo Estado como contrapartida à ampliação gratuita dos cursos de qualificação à população mais vulnerável, sem terem cumprido com tal contrapartida. Na verdade, o que prevaleceu como prática corrente dos ofertantes privados do programa foi uma "seleção de 
clientelas", preterindo um tipo de oferta que acabou privilegiando os grupos que virtualmente poderiam arcar com os custos dos cursos de qualificação profissional.

Assim, na ponta do sistema (isto é, nos municípios), os ofertantes privados operaram muitas vezes como os provedores exclusivos dos cursos de qualificação, desvirtuando as finalidades do programa através da promoção de uma oferta de cursos desconexa à necessidade de aprimoramento socioprofissional da população excluída do mercado formal de trabalho.

\section{Conclusão}

Como se pode entrever neste estudo, um dos principais desafios de política pública no Brasil, durante o triênio 2011-2013, foi melhorar as condições de acesso às informações ocupacionais de grupos em situação de vulnerabilidade. Se o principal objetivo da política pública redistributiva é estruturar a ação coletiva de grupos em situação de privação, cujos problemas não possuem consistência sociológica imediata (isto é, não possuem visibilidade), entende-se que a abordagem intersetorial desses problemas pelos poderes públicos é um instrumento valioso para se atingir tal objetivo.

É através desse instrumento que se promove uma articulação mais permanente entre diferentes burocracias, atores políticos e sociais, com vista a suplantar as dificuldades que esses grupos possuem de acessar seus direitos sociais básicos, como o direito ao emprego. Tal articulação requer mobilização, comprometimento e capacidade dos agentes burocráticos, tornando as situações críticas identificáveis e passíveis de intervenção pública.

Entre 2003 e 2016, o governo brasileiro trilhou uma trajetória exitosa de combate à pobreza e redução das desigualdades sociais ao promover a articulação de iniciativas intersetoriais no campo da proteção social. Coube à burocracia ativar a articulação dessas iniciativas. Importantes instrumentos de política pública pertinentes à área da assistência, como o Cadastro Único, foram colocados em curso para viabilizar políticas de inclusão produtiva implementadas através do Pronatec, trazendo resultados bastante positivos.

É de se esperar, portanto, que o sistema brasileiro de proteção social se consolide através da articulação das políticas públicas de assistência e de qualificação profissional, atacando frontalmente os problemas de insuficiência de renda e de trabalho das famílias mais vulneráveis. É também de se esperar que a recente trajetória civilizacional de combate às desigualdades no país continue sendo "puxada" por um engajamento ativo de sua burocracia, dadas as características inerciais da sociedade brasileira, marcada por certo imobilismo de suas pautas redistributivas.

Como comentário final, pode-se sugerir uma regularidade no agir da burocracia brasileira vinculada à questão social. Essa regularidade revela-se em duas conjunturas bastante específicas: a primeira durante as décadas de 1930 e 1940, período de consolidação da legislação trabalhista e sindical; e a segunda nas duas primeiras décadas 
do presente século, momento de implementação das políticas de assistência social previstas na Constituição de 1988.

As mesmas estratégias lançadas nas décadas de 1930 e 1940, visando atenuar os problemas oriundos de um mercado de trabalho com pouca densidade organizativa ao conferir proteção ao trabalhador por meio de sua inscrição profissional e sindical compulsórias, foram utilizadas no Brasil democrático governado por uma coalizão de centro-esquerda, na década de 2000, ao se utilizar de instrumentos burocráticos e de coordenação para criar, de "cima", uma institucionalidade que desse consistência organizativa e prática às tarefas de erradicação da pobreza e de inclusão produtiva.

Não importa o quão distantes estejam o Cadastro Único e a Busca Ativa da Carteira Profissional de Trabalho, do Imposto Sindical e da sindicalização compulsória, em termos dos diferentes ambientes políticos em que foram criados e dos motivos ideológicos que os inspiraram. Todos esses instrumentos de inscrição da população para finalidades de proteção social foram utilizados, intencionalmente ou não, para encaminhar direitos sociais numa ordem social refratária a esses mesmos direitos.

Não é nenhum exagero postular tal comparação, visto que a burocracia brasileira afeta aos temas do trabalho e da proteção social sempre se pautou por um tipo de agir por antecipação; um agir precipitado sobre os "reais interesses da sociedade", mas um agir sociologicamente informado, pois defrontado com a difícil tarefa de implementar decisões de impacto redistributivo sob a égide do conservadorismo da sociedade.

Afinal, se parte da sociedade brasileira foi sempre refratária aos direitos dos trabalhadores, mesmo que o poder organizado do trabalho se apresentasse a ela como uma "ameaça", por que essa mesma parte, sempre relutante, comportar-se-ia de forma diferente diante de políticas destinadas a setores caracterizados pela privação e pela inércia? A resposta para esta questão encontra-se no atraso dessa sociedade. $E$ é neste atraso que se ocultam também as razões que justificam o ativismo do Estado brasileiro na construção da proteção social.

\footnotetext{
Notas

1 Além disso, incrementou-se significativamente os fundos públicos para o financiamento dos programas de geração de trabalho e renda (Fundo de Amparo ao Trabalhador - FAT; Fundo de Garantia por Tempo de Serviço - FGTS) (Cardoso Jr., 2013).

2 Serviço Nacional de Aprendizagem Industrial (Senai), Serviço Nacional de Aprendizagem Comercial (Senac), Serviço Nacional de Aprendizagem do Transporte (Senat) e Serviço Nacional de Aprendizagem Rural (Senar).

3 Com o afastamento da Presidente Dilma Rousseffem setembro de 2016, o MDS foi transformado em Ministério do Desenvolvimento Social e Agrário (Lei no 13.341, de 29/09/2016).

${ }^{4}$ Trata-se de um registro administrativo que traz informações detalhadas sobre as famílias de baixa renda em todo o país. São 24.1 milhões de famílias, das quais 87,3\% têm renda abaixo de meio salário mínimo per capita. Ele permite, em suma, que o poder público conheça cada uma das 74.3 milhões de pessoas que compõem essas famílias (Amaral 2014).
} 


\section{Referências Bibliográficas}

AMARAL, A. D. O papel do Cadastro Único no Plano Brasil Sem Miséria. In: CAMPELLO, T.;

FALCÃO, T.; COSTA, P. V. da. (Orgs.). O Brasil sem Miséria. Brasília: MDS, 2014, p.97-126.

BICHIR, R. M. Capacidades estatais para a implementação de programas de transferência de renda: os casos de Brasil, Argentina e África do Sul. Texto para Discussão, n. 2032, Rio de Janeiro: Ipea, p.1-54, 2015. Disponível em: <www.ipea.gov.br/portal/images/stories/PDFs/TDs/td_2032. pdf>. Acesso em: 21 jun. 2015.

BOLTANSKI, L.; THÉVENOT, L. On justification: economies of worth. Princeton, New Jersey: Princeton University Press, 2006.

BRASIL. Ministério da Educação. Manual de Gestão da Bolsa-Formação-Pronatec. Brasília: MEC, 2011. Disponível em: <www.pronatec.mec.gov.br/images/stories/pdf/manual_bolsa_formacao. pdf>. Acesso em: 18 mar. 2015.

Ministério do Desenvolvimento Social e Combate à Fome. Programa Nacional de Promoção do Acesso ao Mundo do Trabalho - Acessuas Trabalho. Brasília: MDS, 2012. Disponível em: <www.mds.gov.br/assistenciasocial/protecaobasica/1apresentacao-acessuasatualizado-2013.pdf> Acesso em: 20 abr. 2015.

Ministério do Desenvolvimento Social e Combate à Fome. Pronatec Brasil sem Miséria. Brasília: MDS, 2013. Disponível em: <www.mds.gov.br/brasilsemmiseria/arquivos/Pronatec BSM_nova_04.2013.pdf>. Acesso em: 12 jun. 2015.

CARDOSO, A. M. Ensaios de sociologia do mercado de trabalho brasileiro. Rio de Janeiro: Ed. FGV, 2013.

. A construção da sociedade do trabalho no Brasil. Uma investigação sobre a persistência secular das desigualdades. Rio de Janeiro: Ed. FGV, 2010

CARDOSO JÚNIOR, J. C.; JACCOUD, L. Políticas sociais no Brasil: organização, abrangência e tensões da ação do Estado. In: JACCOUD, L. et al. (Orgs.). Questão social e políticas sociais no Brasil contemporâneo. Brasília: IPEA, 2005, p.181-260.

CARDOSO JÚNIOR, J. C. Mundo do trabalho e (des)proteção social no Brasil, vol.1. Rio de Janeiro: Azougue Editorial, 2013.

CASTEL, R. As metamorfoses da questão social. Uma crônica do salário. Petrópolis: Ed. Vozes, 1998.

COSTA, P. V. da. et al. A estratégia de inclusão produtiva urbana no Plano Brasil sem Miséria. In: CAMPELLO, T.; FALCÃO, T.; COSTA, P. V. da. (Orgs.). O Brasil sem Miséria. Brasília: MDS, 2014, p.289-321.

DEAN, H. The ethics of welfare-to-work. Policy and Politics, v.35, n.4, p.573-589, 2007.

DIEESE. Rotatividade e flexibilidade no mercado de trabalho. São Paulo: Dieese, 2011. p. 1-119.

Disponível em:<www.dieese.org.br/livro/2011/livroRotatividade11.pdf >.Acesso em 14 fev.2015.

DUBAR, C. Réflexions sociologiques sur la notion d'insertion. In: CHARLOT, B.; GLASMAN, D.

(Coord.) Les jeunes, l'insertion, L'emploi, Paris: PUF, 1998, p. 30-38.

DUBET, F. Le places et les chances: repenser la justice sociale. Seuil: Paris, 2010.

DWYER, P. Creeping conditionality in the UK. Canadian Journal of Sociology, v.25, n.2, p.261-283, 2004.

FITOUSSI, J-P., ROSANVALLON, P. Le nouvel âge des inégalités. Seuil: Paris, 1996.

GUIMARÃES, N. A. Trajetórias inseguras, autonomização incerta: os jovens e o trabalho em mercados sob intensas transições ocupacionais. In: CAMARANO, A. A. (Org.) Transição para a vida adulta ou vida adulta em transição? Rio de Janeiro: Ipea, 2006, p. 171-198. 
."O que muda quando se expande o assalariamento (e em que o debate da sociologia pode nos ajudar a compreendê-lo)"? Dados, v. 54, n. 4, p. 533-568, 2011.

HASENBALG, C. A transição da escola ao mercado de trabalho. In: HASEMBALG, C.; SILVA, N. V. (Orgs.). Origens e destinos: desigualdades sociais ao longo da vida. Rio de Janeiro: IUPERJ/ TopBooks, 2003, p. 147-172.

LANZARA, A. P. Capacidades estatais, trabalho e seguridade social: África do Sul, Argentina e Brasil em perspectiva comparada. Texto para Discussão n. 2052, Brasília: Ipea, p. 1-54, 2015. Disponível em:<www.ipea.gov.br/portal/images/stories/PDFs/TDs/td_2052g.pdf >. Acesso em: 10 abr. 2015.

LASCOUMES, P.; LE GALES, P. Understanding public policy through its instruments-from the nature of instruments to the sociology of public policy instrumentation. Governance, vol. 20, n. 1, p. 1-21, 2007.

MÉDA, D. Le travail, une valeur en voie de disparition. Paris: Aubier, 1995.

NOZICK, R. Anarchy, state and utopia. New York: Basic Books, 1974.

OLIVEIRA, F. Economia brasileira: crítica da razão dualista. São Paulo: Cebrap/ Petrópolis: Vozes, 1972.

RIFKIN, J. The end of work: the decline of the global labor force and the dawn of the post-market era. New York: G.P. Putnam's Sons, 1995.

ROSANVALLON. P. La légitimité démocratique. Impartialité, réflexivité, proximité. Paris: Seuil, 2008. SOARES, S. Volatilidade de renda e a cobertura do Programa Bolsa Família. Texto para Discussão n. 1459, Rio de Janeiro: Ipea, p. 1-20, 2009, Disponível em: <www.ipea.gov.br/portal/images/ stories/PDFs/TDs/td_1459.pdf.>.Acesso em 12 fev. 2015.

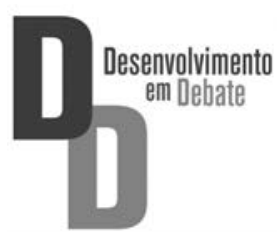

